\title{
Juan Campo
}

\section{neoliberalismo y catolicismo: la doctrina de la libertad económica*}

"No se puede dejar al desarrollo ni al libre juego de las fuerzas económicas ni a la sola decisión de la autoridad pública. A este propósito hay que acusar de falsas tanto las doctrinas que se oponen a las reformas indispensables en nombre de una concepción falsa de la libertad como las que sacrifican los derechos funda mentales de la persona y de los grupos en aras de la organización colectiva de la producción."

Esquems XIII, núm. 65.

El año 1954 el profesor Oswald von Nell-Breuning manifestaba: «El neoliberalismo se precia de que sus principios son auténticamente cristianos, que posee un Ethos cristiano proyectado a la economía y que ofrece una regla de comportamiento a tenor de la doctrina neoliberaln?

Un año después, Daniel Villey, entonces catedrático de Economía Política de la Universidad de Poitiers, escribía: «En casi todos los países, los votos de los católicos, en su mayoría, son para los partidos conservadores que, oficialmente o en la práctica, son liberales ${ }^{2}$.

En 1963, en el prólogo a la versión española de una obra de MüllerArmack, titulada "Economía dirigida y economía de mercadon, se dice: aEs conocida de todos la vinculación de la política neoliberal con los movimientos católicos...; la insistencia del cristianismo sobre

* Ofrecr nos un capítulo de un extenso estudio comparativo, basado en la obra del filósofo y economista alemán $W$. Röpke.---(N. de la R.)

1 Von Nell-Breuning, Oswald, Wirtschaft und Gesellschaft heute, T. III, Zeitfragen 1955-1959, p. 90. Verlag Herder. Freiburg, 1960.

2 "La Economía de mercado ante el pensamiento católico», por Daniel Villey, pp. 65-115 de la obra aLa Economía de Mercadon, publicada por la Sociedad de Estudios y Publicaciones. Madrid, 1963. T. II. 
los valores individuales habia de llevarle a un terreno común con las ideas que hemos expueston (neoliberales) ${ }^{3}$.

Estos datos nos bastan para hacernos esta pregunta: ¿Hasta qué punto se puede decir que los principios del neoliberalismo son principios auténticamente católicos? $Y$ en último término, ¿cuál es la doctrina católica sobre la libertad económica?

A pesar de lo dicho anteriormente, la tesis principal del profesor Villey tiene un signo ambivalente: el catolicismo ha sido y es antiliberal, pero puede y debe encontrar sus puntos comunes con el neoliberalismo ${ }^{4}$. Aunque sea cierto, según Villey, que «las dos naciones en las que desde la segunda guerra mundial partidos de inspiración católica han tenido el poder-Alemania e Italia, a las que se podría añadir Bélgica-son las que han seguido una política económica más ortodo$x a$ desde el punto de vista liberal», sin embargo, es también verdad que "los teólogos y los economistas católicos repudian, casi todos, el liberalismo económico y lo hacen con frecuencia en nombre de su fen ${ }^{5}$.

Wilhelm Röpke, fervoroso calvinista y perspicuo conservador, comprueba también esa palmaria contradicción entre doctrina y práctica; con un gesto un tanto ecumenista se dirige a Daniel Villey con esta pregunta referida expresamente al catolicismo: " $i$ Es necesario ser agnóstico para ser economista liberal?: El católico Villey se ve tentado ante la evidencia de ciertos hechos a responder afirmativamente. Pero una serena actitud le lleva a insistir reflejamente sobre las razones por las cuales los católicos adoptan, al menos doctrinalmente, una postura antiliberal ${ }^{\text {. }}$.

3 "Economía dirigida y economía de mercado", Alfred Müller-Armack, Sociedad de Estudios y Publicaciones. Madrid, 1963, p. 45 del prólogo a la versión española, escrito por Ramón Trias Fargas.

4 Este segundo aspecto es, a juicio nuestro, lo más positivo y digno de encomio en su trabajo, por lo que supone de empeño y noble esfuerzo. En todo caso, para pronunciar un juicio recto sobre el artículo, es preciso tener en cuenta que el estudio de Villey atiende casi exclusivamente al catolicismo francés.

En nuestra opinión, constituye un fallo la insistencia del autor sobre o en torno al liberalismo histórico; ipor qué pretender justificar lo injustificable? Si Röp$\mathrm{ke}$, antor neoliberal, enemigo acérrimo del antiguo liberalismo, le formula esa pregunta, creo que lo acertado era el intento de unir el neoliberalismo presente, como defensor de la economía del mercado, con el catolicismo presente, siempre viejo, pero también siempre nuevo.

5 Villey, artículo cit., p. 65.

6 Ibid., p. 66. El trabajo de Villey trata de explicar por qué los católicos adop" tan una postura antiliberal, y quiere refutar las razones doctrinales que aducen. Tras la denuncia acertada-a nuestro juicio-de algunos hechos, critica con desigual exactitud y acierto los argumentos aducidos por ciertos sectores del pensamiento católico. En la segunda parte pretende establecer los fundamentos de un liberalismo económico católico.

7 Antes de seguir adelante resulta obligada una observación previa. Se refiere a la distinción de planos entre catolicismo y neoliberalismo. El primero trasciende al segundo. El catolicismo es una religión. El mensaje vital de Jesucristo contiene la redención de almas y cuerpos, pero la Iglesia tiene como fin primario la salvación de las almas. El neoliberalismo económico es una doctrina económica. Por otra parte, no existe una doctrina económica católica única. En principio, podrían elaborarse diferentes doctrinas económicas a la luz de la fe y animarlas del espíritu católico. 


\section{FUNDADA PREVENCIÓN FRENTE A LO "LIBERAL"}

Las prevenciones o reservas que formulan los católicos ante el pensamiento neoliberal económico se deben a cuatro motivos diferentes. El primero, la ignorancia del funcionamiento de la economía de mercado no es motivo exclusivo de los creyentes ${ }^{8}$. Los otros tres motivos son mas bien tendencias sectoriales del pensamiento católico, que se pueden clasificar bajo los nombres de "integrismo", "moralismo» y "profetismo». Nos ocuparemos aquí del integrismo".

Si cierto sector del pensamiento católico retrocede ante la doctrina económica de mercado libre es porque viene acompañada del marchamo «liberalismon, "liberal" y otros adjetivos semejantes. Hay una fuerte irradicación afectiva. Libre competencia y mercado libre evocan tristes experiencias. Por su parte, la palabra «liberalismon-aunque vaya con frecuencia precedida por el prefijo neo-lleva un lastre de maldad que pesa aún mucho en la consideración católica ${ }^{10}$. Se ha cargado de tales polos negativos a lo largo del tiempo, que aun hoy día a algunos esta palabra «evoca el libre examens, el indiferentismo religioso, el escepticismo, el desconocimiento y negación del principio de autoridad tanto en materia religiosa como en política. A los ojos de muchos católicos el liberalismo es un bloque: un bloque de ideolo. gías anticatólicas» ${ }^{11}$.

Aquí creemos preciso aclarar incluso al propio Villey, que entre el paleoliberalismo y el neoliberalismo hay diferencias esenciales que no se reducen exclusivamente al tiempo de aparición de ambas ideologías; los principios neoliberales difieren sustancialmente de las tesis clásicas liberales ${ }^{12}$.

8 Tiene bastante razón el profesor Villey cuando viene a decir que hoy dia toda persona habla, discute y adopta posiciones en materia económica; pero pocos comprenden el mecanismo de los precios. "El tipo, muy extendido, de intelectual cátólico que no es especialista, pero está interesado en la teoría económica, posee generalmente una biblioteca extrañamente compuesta. Tiene las obras completas de Santo Tomás de Aquino y de Karl Marx. Sin embargo, es raro que hayan leído a Adam Smith o a Bastiat, o incluso a Keynes, que debe resultar, evidentemente, incomprensible a cualquiera que desconozca los clásicos." (Villey, art. cit., p. 85). "Con frecuencia el desconocimiento de las leyes económicas se deja entrever en las pastorales de los Obispos." (Ibid., p. 86.)

${ }^{9}$ Es preciso reconocer que la objeción integrista en algunos momentos está expuesta un tanto burdamente por Villey. Por otra parte, la objeción social sería uno de los reproches más certeros y mejor fundados que la doctrina social católica puede hacer al pensamiento neoliberal. Con relación a Röpke, concretamente tenemos pensado analizar su ideología social en comparación directa con el pensamiento católico en un trabajo posterior.

${ }_{10} \mathrm{El}$ propio Villey aduce el recuerdo de libros como aEl liberalismo es pecadon, de Félix Sardá y Salvanyn, cfr. ib., p. 97, nota 36. En el texto correspondiente a esa nota dice: "Ha habido algunos católicos-o campeones del catolicismo, no creyentes, como Charles Maurras-que han formulado una especie de caricatura del catolicismo.n

i1 lbid,y pp. 89-90.

12 Aunque los dos sistemas defienden la economía de mercado y la competencia libre como fundamento básico de la actividad económica, to hacen bajo supuestos y condiciones a veces diametralmente opuestos. Si no admitimos esta dife- 
Admitida esa diferencia la pregunta que cabe formularse es la siguiente: ¿Hasta qué punto o en qué medida el neoliberalismo de nuestros dias es compatible o no con el catolicismo? Tal vez entonces la objeción católica, apoyada sobre todo por el bando integrista, insistiera de nuevo, por esa irradiación afectiva indicada y no por razones objetivas, sobre el problema de la libertad. La ideología neoliberal tiene un concepto de libertad diferente a la concepción católica de la misma ${ }^{13}$. La dificultad está bien puesta.

El profesor Villey se dio cuenta de que aquí estaba efectivamente uno de los puntos vulnerables de la doctrina neoliberal. Por eso, al tratar de ver "cómo es posible concordar el arpa de David con ese canto de cisne-o de gallo-que lanza hoy el liberalismon, realiza un esfuerzo notable para resolver esa dificultad. Su argumento más fuerte es la fundamentación de la libertad humana en la trascendencia divina ${ }^{14}$.

"Si Dios trasciende al mundo, si descansó de su creación después del sexto día, el mundo existe fuera de Dios, es distinto de Dios; la naturaleza es autónoma en relación con la gracia, tiene sus propias leyes y todo lo que no es sobrenatural en el hombre-la sociedad temporal, "le gros animal" de Simone Keil-tiene sus propias leyes también que son naturales. Hay un laicismo basado en el indiferentismo y en el agnosticismo, pero existe otro que se funda en la trascendencia de la esfera religiosa en relación con la sociedad. La fe, la gracia en el hombre, son renovados por Dios en cada instante. Pero el mundo en sí, una vez creado, "marcha por sí mismon, según la expresión de los fisiócratas

"La idea de la trascendencia lleva a una visión pluralista del mundo. La trascendencia es el principio fundamental de la heterogeneidad de todo lo que existe. A quienquiera que perciba zanja abierta entre Dios y el mundo le parecerá familiar una visión de la discontinuidad de este mundo tal como la postulan los liberales. El espiritu católico, por tanto, está preparado para admitir la heterogeneidad irreconciliable de los intereses, la multiplicidad de los centros de decisión económica y la autonomía de lo económico con lo políticon ${ }^{15}$.

Ignoramos si Röpke quedó satisfecho con la respuesta dada por el profesor Villey a su pregunta. Desde el lado católico reconocemos todo

rencia no podemos seguir adelante. Aclaremos nuestro pensamiento. Con esto no agrupamos en un solo y mismo bloque a todos los autores que se llaman o son llamados neoliberales; de ninguna manera. Precisamente boy más que nunca interesa poner en evidencia las reminiscencias viciosas y atávicas de muchos de ellos, lo mismo que aquello que de inaceptable pueda tener el más depurado y auténtico neoliberalismo. Algo de esto pretendemos en estas páginas. De igual modo, en el terreno de las realidades económicas convendrá distinguir bien el trigo de la cizaña. También al amparo de principios neoliberales se pueden adoptar medidas que tengan sabor manchesteriano más o menos concentrado.

13 Como ejemplo más llamativo para ver la objetividad de tal objeción se podría aducir la teoría de F. A. Hayek sobre la libertad, publicada por Fomento de Cultura, Ediciones Valencia, dos tomos.

14 a $\mathrm{La}$ idea central que debernos poner de manifiesto es la siguiente: la idea de libertad, si bien históricamente, procede del escepticismo, puede ser fundada también en la trascendencia divinan. Volley, art. cit., pp. 121-122.

is Ibid., pp. 122-123. 
lo bueno que hay en el propósito del profesor francés, pero comprobamos la inconsistencia de su argumentación. La armonización pretendida falla, a juicio nuestro, en la fundamentación teológica.

\section{UNIDAD DE LO TRASCENDENTE Y LO MUNDANO}

Es cierto que Dios trasciende el mundo e hizo al hombre libre; pero no se desentiende ni del uno ni del otro ${ }^{16}$. La heterogeneidad de todo lo creado y la conformación pluralista de nuestra existencia humana no postulan ni demuestran la discontinuidad de las realidades terrenas con Dios. Esa "zanja abierta" entre el Creador y el mundo, aunque es infinita de verdad, ha quedado ya de hecho cerrada con la Encarnación del Hijo de Dios. Y en definitiva la teología de la Redención no lleva a una concepción unitaria de todo el universo creado: el hombre y las demás criaturas forman parte integral del objetivo, dominio y elevación redentores.

Sea como fuere, nuestro personaje, Wilhelm Röpke, parece estar convencido de la compatibilidad teórica entre la ideología neoliberal y el catolicismo; y una comprobación de su convicción era lo que buscaba. En sus obras nos ha dejado escrita una frase elocuente, que pone de manifiesto esa convicción suya de que hablamos: "El cristiano es un liberal que se desconoce ${ }^{17}$. Esto nos plantea un problema de interpretación.

Cuando el profesor Röpke afirma eso, ¿qué quiere dar a entender? El significado de tal expresión en labios de Röpke, aunque no sea original suya, parece ser el siguiente: el liberal tiene y radica en la libertad como un valor central esencial; y el católico, lo mismo. Tal vez éste no se dé cuenta reflejamente; pero su actitud total religiosa está fundamentada en la libertad; el católico es por esencia un «liberals ${ }^{18}$.

$\mathrm{Si}$ nuestra interpretación es sustancialmente acertada, entonces la cuestión se traslada a estas otras preguntas: ¿Se trata en los dos casos efectivamente de un valor fundamental? $Y$ en caso afirmativo, ise entiende esa libertad en el neoliberalismo y el catolicismo del mismo

18 Von Nell-Breuning, gran conocedor de Röpke y de su obra, interpreta esta frase en el sentido indicado y cree que tal dicho en labios de Röpke no es un juicio rápido e impensado, sino que encierra la expresión formal de un convencimiento serio.

12 Para una ampliación de estas ideas remitimos a la obra, de Gustavo Thils, "Teología de las realidades terrenas", I Preludios, Ediciones Desclés de Brouwer, Buenlos Aires, 1948, y de manera concreta al apartado "Dios y la creación del mundon, pp. 81-87.

17 Encontramos esta expresión de W. Röpke al menos en su obra «Civitas Humanax, Libraire de Médicis, Paris, 1946, p. 12: "Un bon chrétien est un libéral qui s'ignore». $O$. von Nell-Breuning pone también en boca de Röpke esta afirmación, dice que es original de Tocqueville, pero no refiere cuándo y dónde lo dicen uno $y$ otro, "Un chrétien est un libéral qui s”ignore». La traducción alemana es: "Ein Crist ist ein Liberaler, der sich dessen nicht bewusst ist». Cf. von Nell-Breuning; op. cit., p. 90 y nota 4 . 
sentido? ¿O más bien nos encontramos aquí con una coincidencia de palabras, e incluso de conceptos, pero que no tienen un mismo e idéntico sentido?

Si analizamos cada uno de los dos términos o sujetos que se pretende comparar, lo primero que hemos de tener en cuenta es la diferencia de planos de ambos términos ${ }^{19}$. Esto supuesto, el neoliberalismo se puede considerar como un sistema de ordenación social y económica que proclama la líbertad como su valor central ${ }^{20}$. En el catolicismo no ocurre eso... Es cierto que el catolicismo considera la libertad como uno de los valores supremos del hombre y de la sociedad. Pero como religión trascendente el catolicismo no puede tener más que un valor central: Cristo.

Aunque diéramos por supuesto lo anterior, la libertad no es entendida por el catolicismo y por el neoliberalismo, en cuanto ideologías doctrinales de una idéntica manera ${ }^{21}$. Los dos hablan conceptualmente de libertad y buscan además un contenido objetivo de la misma. Resultaría un tanto ingenuo el pensar que ambos utilizan casualmente una misma palabra para designar dos realidades completamente diferentes ${ }^{22}$.

\section{DOS DEFINICIONES DE LIBERTAD}

El neoliberalismo parece entender el concepto de libertad insistiendo mas bien en el sentido negativo del mismo. El principio que enunciara tal concepción sería el siguiente: el campo de acción (el espacio) de mi decisión interna como el de mi actuación externa no deben sufrir limitación alguna por parte de ninguna causa. Sin embargo, como de hecho alguna clase de limitaciones es inevitable, entonces ha de va-

19 Ya lo hemos indicado al comienzo de estas disquisiciones en la nota 7.

20 Aun con todos los recortes que el mismo Röpke marca a la actividad económica y política del hombre neoliberal, la nota más distintiva y característica de su sistema de economía libre es, sin duda, la libertad; una libertad, por otra parte, bien entendida - digámoslo una vez más---, no al estilo decimonómico.

21 Estamos comparando catolicismo y neoliberalismo en una esfera teórica. E incluso, si queremos extender la comparación al hombre, podríamos hacerlo de esta forma: el católico-en cuanto católico--no entiende la libertad de la misma manera que el neoliberal en cuanto neoliberal-. Es evidente que, aun ast, se trata de una abstracción; pues fulano de tal, católico y neoliberal a la vez, podria vivir y actuar dentro de la más completa ortodoxia, tanto con relación a su fe religiosa como a sti doctrina social económica. El estudio de esta posibilidad y convivencia teóricas y prácticas es uno de los objetivos al cual tienden nuestras consideraciones.

22 Partiendo de la experiencia--y supuesta la radicación en una filosofía no predeterminista-todos reconocemos en primer lugar que la libertad es una potencia o cualidad del hombre que se manifiesta ordinariamente en actos y realizaciones externas. De igual manera coincidimos seguramente al distinguir, dentro de cualquier acto libre, los dos aspectos del mismo: el negativo, que consiste en la ausencia de coacción externa e interna; y un segundo aspecto positivo, la faculad de determinarse a sí misma que tiene la voluntad de todo hombre libre. 
ler el principio formal de que el ejercicio de mi libertad no ha de ser estorbado por la misma libertad de otros, y viceversa.

El concepto católico de libertad consiste en lo siguiente: yo tengo libertad (facultad) para decidirme en mi interior tal como a mí me parece justo y recto en mi responsabilidad ante Dios. Es cierto que nadie puede entrometerse en mi decisión; de ahí que ningún poder creado, sea el del Estado o cualquier otro, puede coaccionar mi libertad ${ }^{23}$.

Desde el punto de vista católico queda establecido claramente un principio material objetivo: mi libertad es equivalente a mi responsabilidad personal ante Dios y, respecto a su uso lícito, está limitada por las normas de la ley moral. Esto no quiere decir que el neoliberalismo niegue las normas morales; pero su concepto de libertad tiene una acuñación formal y la practicabilidad de tal principio formal es muy discutible ${ }^{24}$.

Además, desde la perspectiva católica, en cuanto tal, se considera como algo esencial el contenido material de aquello a lo cual nos decidimos con nuestra libre voluntad. El neoliberalismo no parece distinguir y considera la libertad como un bloque compacto. Por esto, para el catolicismo, los atentados posible contra la libertad de los hombres tendrán valoraciones o agravaciones diversas, según sea el objeto que busque y pretenda la contrariada decisión humana. La libertad económica del hombre, por ejemplo, aunque es un aspecto importante de la libertad integral humana, es inferior a la libertad religiosa.

Por lo dicho creemos que existe una diferencia considerable entre el concepto católico de libertad y el neoliberal. Pero con esto no queremos decir que el segundo niegue el primero, ni siquiera que los ex. cluya; sencillamente los dos conceptos tienen un contenido distinto que convenía poner de manifiesto ${ }^{25}$.

De aquí tomamos pie para ensayar una estructura esquemática de la doctrina católica sobre la libertad del hombre en su actividad eco. nómica. El profesor Röpke podría decirnos al final si estamos o no de acuerdo con él, o si él está de acuerdo con nosotros.

Para lograr el objetivo indicado es preciso que arranquemos de la dignidad del hombre. La dignidad esencial del hombre comprende, en-

${ }^{23}$ La vinculación de la responsabilidad personal a la libertad es evidente; sin libertad no puede haber responsabilidad, y éste es una consecuencia inmediata de la primera.

En estas consideraciones seguimos el pensamiento de nuestro antiguo maestro en Frankfurt, $O$. von Nell-Breuning, S. J., profesor de Teologia Dogmática en la Phil-Theologische Hochschule Sankt Geogen, en Frankfurt, profesor de la Facultad de Ciencias Económicas y Sociales de dicha ciudad; miembro desde 1948 del Consejo Científico del Ministerio de Economía de la República Federal y del Comité del Ministerio Federal de problemas relativos a la familia y juventud.

24 Acerca del concepto de libertad en Hayek, véase, por ejemplo, la crítica que el profesor Robins hace a la tesis que Hayek expone en su libro ya citado "The Constitution of Liberty, "El concepto de libertad del profesor Hayek, como el de los grandes pensadores liberales del pasado, se expresa en términos de ausencia de coerción arbitraria». Cf. Información Comercial Española, agosto 1961, pp. 63-75.

${ }^{25} \mathrm{Los}$ dos conceptos sustancialmente no son contrarios ni contradictorios; pueden ser complementarios. Otra cosa debería decirse del concepto de libertad y las correspondientes implicaciones del mismo como lo expone Hayek. Su crítica y comparación con el concepto católico nos llevarian demasiado lejos. 
tre otros aspectos, los siguientes: El hombre es persona corporal que se posee de forma consciente y libre. Está objetivamente referido a sí mismo; tiene siempre, por tanto, carácter de fin en su propio ser ontológico; nunca carácter de medio ${ }^{26}$. Posee, por consiguiente, un valor absoluto. En esto radica su respetabilidad y su profunda dignidad, al margen de cualquier valoración y finalidad.

El hombre es al mismo tiempo una persona que tiene una serie de proyecciones al exterior a las cosas y personas. En primer lugar, ha de ejercitar una actividad que le procure los bienes necesarios para su existencia corporal (actos económicos). Para efectuar tal actividad necesita, de forma indispensable, medios y espacio (tierra, empresa, economía, etc.), con los que lleva a cabo su autorrealización. Pero todos los medios, realidades y valores que tienen carácter de cosa no poseen valor absoluto ni el distintivo de fin. Dichas cosas están orientadas al hombre y tienen siempre carácter de medio; están condicionadas por una valoración y elección libre y personal del hombre.

Esas diversas proyecciones existenciales del hombre-entre las cuales está su quehacer económico-se encuentran condicionadas entre si. Hay una cierta autonomía relativa de tales dimensiones o proyecciones, pero no independencia completa, ya que el hombre es uno en su origen y en su fin, a pesar de su propia variedad constitucional. Así, por ejemplo, no se da una autonomía total de la dimensión económica del hombre, con normas autónomas que no tengan en cuenta las otras proyecciones del hombre completo y sus leyes correspondientes. Por eso hay una jerarquización dentro de las dimensiones existenciales del hombre, y en caso de litigio las superiores prevalecen a las inferiores. El aspecto económico se subordina al ético, si existe oposición entre ambos.

Por otra parte, el hombre, como poseedor de una orientación esencial hacia las personas, forma comunidades humanas con ellas: familia, asociaciones, estado, etc.

Tras estos supuestos, la libertad es la posibilidad que tiene el hombre de adoptar una postura ante Dios de forma general y responsable. La libertad humana, así entendida, es un don creado y un dato de la teología ${ }^{27}$. No puede concebirse la libertad como una facultad formal que adquiera su significado sólo del resultado obtenido por ella, pero distinto de la libertad misma.

La libertad económica es una parte de la libertad integral del hombre. Viene a ser la posibilidad de autorrealización de la persona humana en su proyección económica. La libertad humana-y, por tanto,

26 A nadie extrañará este carácter de fin que asignamos al hombre referido a su propia entidad ontológica. Se sobreentiende en un esquena universal que el único y auténtico fin del hombre y de las cosas es el Creador del universo. Dios, principio y fin de la existencia entera. Lo mismo se debe entender al decir que el hombre posee un valor absoluto.

27 Efectivamente, el tratado dogmático "De Gratian considera la libertad del hombre como una verdad revelada, y a su vez como uno de los fundamentos esenciales para la doctrina de la gracia. Sin la existencia de la libertad del hombre no tendría responsabilidad ninguna ante cualquier clase de gracia concebida por Dios. 
también la económica-presupone, entre otros prerrequisitos internos y externos una ley de orden ontológico y ético. Tales prerrequisitos son variables y limitan las posibilidades de la libertad. Aquí radica la razón ética de una limitación legítima de la libertad económica. Concretamente la ley moral presupone libertad, va dirigida a ella y la orienta hacia su propio fin esencial: la autorrealización de la persona, La ley moral así entendida, no implica por consiguiente una restricción de la libertad económica.

No puede existir una norma ética de igualdad absoluta para las posibilidades de la libertad económica. Sin embargo, esas posibilidades de actuación de la libertad económica exigen un marco suficiente para su realización. La suficiencia de dicho marco vendrá dada por la medida de los diversos lados (político, social, jurídico, moral) que configuran el libre y compatible quehacer económico del hombre, grupo o nación.

\section{LA PRÁCTICA DE LA LIBERTAD ECONÓMICA}

Ya de por sî el terreno de aplicación y actuación de la libertad económica es variable y finito, y aun en una misma persona, grupo o na. ción puede cambiar debido a las exigencias que tenga la libertad de otra entidad semejante o no semejante. Se da, por tanto, una limitación justa del margen de acción de la libertad económica. Incluso puede darse una limitación tal, que en sí no sea inmoral, aunque provenga de la actitud voluntaria opuesta de otra persona, física o moral.

Las razones y las maneras como puede concebirse una cierta limitación legítima del campo de acción de la libertad económica son de diverso género. Prescindimos de un estudio detallado. En líneas generales hay un principio general legítimo de libertad económica. Existe otro principio, también legítimo, de justa coacción económica. El primero, sin embargo, es más elevado. El problema surge inmediatamente: cómo delimitar justamente la coacción y la libertad dentro de una general libertad económica ${ }^{28}$.

Desde el punto de vista moral sólo puede justificarse una delimitación que acepte y respete esos dos principios. Ni liberalismo absoluto, ni dirigismo económico totalitario. Por otra parte, resulta imposible señalar una exacta línea divisoria que sirva siempre y para todos los casos. La revelación y la doctrina de la Iglesia no suministran los datos necesarios, ni la segunda puede pretender algo semejante. Aquí, como en otros aspectos, repugna un racionalismo teológico.

De esto último se desprende una serie de consecuencias que inciden en la actuación y en el deber de actuar de los inviduos, grupos y naciones católicos. Admitidos aquellos dos principios, al hombre, en

28 Naturaimente este conflicto entre libertad y coacción puede considerarse-y darse también-en general y en relación con las diversas dimensiones del hombre. Aunque la dimensión económico humana sea inferior en la jerarquía anteriormente admitida-a otras proyecciones del hombre, no deja de tener importancia su consideración y aplicación prácticas. En realidad, en el terreno de los hechos, su ejercicio-el ejercicio de la libertad económica dentro del marco de la actividad del mismo nombre irá unido muchas veces al ejercicio de otras libertades funda mentales de la persona humana. 
cuanto tal y en cuanto católico, le incumbe el deber y la responsabilidad de trazar la línea práctica divisoria entre libertad y coacción económica ${ }^{20}$.

Esa delimïtación será, por tanto, una libre decisión histórica, y ten. drá en cuenta, consiguientemente, las circunstancias objetivas y cambiantes de la situación económica y demás factores concomitantes. Como libre decisión histórica, esa delimitación-además de no ser única ni exclusiva-tampoco puede ser el resultado de una aplicación deductiva de principios formales a situaciones estáticas. Tal decisión tiene el carácter de la originalidad e iniciativa creadoras; pero, al mismo tiempo, como cualquier otra actuación del hombre, bien sea solo, en grupo o en el estado, posee inevitablemente el carácter de riesgo e inseguridad.

El hombre católico tiene, por tanto, también como católico, la obligación de actuar y decidir, y en ocasiones necesitará para ello el coraje de los mártires. Si en toda actuación económica el hombre ha de ser protagonista esforzado de libres decisiones-aun con un margen de riesgo--, se requiere una energía mucho más grande cuando se trata de equilibrar justamente el ejercicio de la libertad y de la coacción económicas ${ }^{30}$.

A veces será necesario un programa de acción económica concreto, y éste, naturalmente, no podrá deducirse de los principios teológicos. Una clara conciencia de la situación le dictará al católico lo que se ajusta más rectamente a sus principios eternos. Además, los diversos aspectos de un problema-aquí concretamente libertad y coacción eco* nómicas--, aunque en teoría sean igualmente considerables, no revisten en cualquier circunstancia para la acción una misma importancia.

Por consiguiente, "el cristianismo ha de tener no sólo el valor de sostener una teoría eterna bien ponderada, sino también el ánimo y la decisión de dar una consigna clara, si bien conectada con el tiempo, que él, en ciertos casos, podrá ostentar en nombre del cristianismo, aunque no sea ni pueda ser publicada por la Iglesia en cuanto tal ${ }^{3 i}$.

"La realización de tales desplazamientos de límites entre libertad y coacción ha de tener lugar, en general, en una evolución, explotando las posibilidades legales de que se dispone. En casos en que la situación del momento implicara una abolición general y considerable de libertades de su derecho natural, su remoción, aun mediante actos revolucionarios, sería lícita desde el punto de vista cristiano, y hasta obli-

29 Aunque el término "coacción" parezca sugerir la presencia de un ser o enidad superior capaz de coaccionar, sin embargo, estas consideraciones se refieren, por ahora principalmente, a los particulares asociados o individualmente capaces rambién de ejercer una coacción de muy diversas clases en el terreno económico.

30 Dentro del campo de la actividad económica libre, los hombres--solos o asociados - podrán llegar a adoptar posturas de compromiso y tanteo, tentativas y decisiones provisionales; evolucionar y emprender otros caminos. Todo esto, en su lugar y tiempo oportuno, es muy característico de la estrategia económica y a la vez una prueba fehaciente de nuestra genuidad humana. Dice Rahner: "Quien crea poder abtir con una llave todas las cerraduras, se arroga una posición divina, miente y no tiene verdadero porvenir». Cf. Escritos de Teología, T. II, p. 265.

3t Rahner, op. cit., p. 266. Lo mismo el párrafo citado siguiente. 
gatoria caso de darse verdaderas perspectivas de éxito para quienes dispusieran de los medios apropiados."

\section{EL ESTADO Y LA LIBERTAD ECONÓMICA}

El Estado es para los hombres; no al revés. El Estado debe servir a la dignidad y libertad del hombre, y, por tanto, también a la libertad económica del mismo.

Ya hemos visto cómo a la esencia del hombre pertenecen en un principio las comunidades humanas, la orientación de dicho hombre hacia un "tún en amor y servicio mutuo. Pero el Estado, aunque es una institución natural, no es la primera y principal de estas comunidades, sino una organización social subsidiaria; ha de servir a esas comuni dades más primigenias y esenciales: familia, gremios profesionales, asociaciones de producción y consumo, etc. El Estado las presupone.

Además, no es el Estado quien otorga sus derechos primigenios y el campo de acción de su libertad económica a los individuos y a los grupos humanos más pequeños; sino que debe protegerlos, regularlos cuando sea preciso y armonizarlos mutuamente. Por tanto, el Estado no debe suponer, sino demostrar, su derecho a limitar la libertad económica en casos concretos. Al practicar tales limitaciones e imponer restricciones a la libertad económica debe atenerse a los principios anteriormente indicados.

Existen principios inmutables de derecho natural y de carácter cristiano que tienen vigor para todo Estado y para toda constitución económica. Todo católico tiene el deber de cuidar que sean observados en el Estado y en la economía ${ }^{32}$. Pero no existe Estado ni constitución económica que se puedan deducir en su forma concreta de esos principios inmutables. Por tanto, los católicos-no la Iglesia-de una época, nación o situación histórica determinada necesitan, además de esos principios, una idea concreta de la forma que debe adoptar la constitución económica nacional de manera especial en lo referente a la delimitación de libertad y planificación económicas en un ámbito macroeconómico.

El hecho de que la Iglesia no pueda-ni deba-precisamente suministrar esta idea o norma concreta no dispensa a los católicos de este deber. Quienes, como católicos, se contenten con los principios eternos y no tengan el valor de organizar su presente y preparar un porvenir económicos, pecan contra la fidelidad a su existencia y se hacen realmente culpables de las consecuencias sociales de su inactividad.

\footnotetext{
${ }^{32}$ Tales son, por ejemplo, entre otros, el derecho de propiedad, derecho al tra bajo y al salario justo. Entre los derechos económicos fundamentales podemos citar la libertad de todo ciudadano de consumir y organizar su vida como corresponda a los deseos e ideas personales del individuo dentro del marco de las posibilidades económicas. Este derecho fundamental democrático a libertad de consumo debe encontrar sl complemento lógico en la libertad del empresario para producir y colocar lo que estime necesario y prometedor de éxito, según las oportunidades del mercado y adaptándose a las prescripciones del orden social.
} 